\title{
Network Meta-Analysis and Cost Per Responder of Tumor Necrosis Factor- $\alpha$ and Interleukin Inhibitors in the Treatment of Active Ankylosing Spondylitis
}

Keith A. Betts · Jenny Griffith • Yan Song • Manish Mittal •

Avani Joshi · Eric Q. Wu · Arijit Ganguli

Received: May 27, 2016 / Published online: July 25, 2016

(C) The Author(s) 2016. This article is published with open access at Springerlink.com

\section{ABSTRACT}

Introduction: Biologic therapies have improved the clinical management of ankylosing spondylitis (AS). Few head-to-head studies have directly compared the efficacy of these agents. This study was conducted to indirectly compare the efficacy of biologic agents for treatment of active AS.

Methods: A targeted literature review was conducted to identify randomized clinical trials for adalimumab, infliximab, golimumab, certolizumab pegol, etanercept, and secukinumab for the treatment of active AS. The clinical efficacy was evaluated using ASAS20 and ASAS40 and synthesized via a Bayesian network meta-analysis. Number needed to treat (NNT) was calculated as the

Enhanced content To view enhanced content for this article go to http://www.medengine.com/Redeem/ 15E4F060775F04F9.

K. A. Betts $(\bowtie) \cdot$ Y. Song · E. Q. Wu

Analysis Group, Inc., Boston, MA, USA

e-mail: Keith.Betts@analysisgroup.com

J. Griffith · M. Mittal · A. Joshi · A. Ganguli

AbbVie Inc., North Chicago, IL, USA reciprocal of incremental response rate of each biologic versus placebo. Comparisons were also made in terms of cost per incremental ASAS20 or ASAS40 responder.

Results: Fifteen studies were identified, which included ASAS20 and/or ASAS40 response rates at Week 12 to Week 16. Patients with AS treated with infliximab had the lowest NNT for ASAS20 of 2.3, followed by those treated with adalimumab (2.8) and etanercept (2.9). Adalimumab had the lowest 12-week cost per additional ASAS20 responder at $\$ 26,888$, followed by infliximab at $\$ 28,175$ and golimumab at $\$ 28,199$. Patients treated with infliximab also had the lowest NNT for ASAS40 (2.6), followed by those treated with adalimumab (2.8) and secukinumab (3.5). Adalimumab had the lowest cost per additional ASAS40 responder at $\$ 26,898$, followed by infliximab at $\$ 32,508$ and etanercept at $\$ 34,406$.

Conclusion: Infliximab had the lowest NNT to achieve an additional ASAS20/40 response, and adalimumab had the lowest cost per ASAS20/40 responder among biologic agents for the treatment of active AS.

Funding: AbbVie. 
Keywords: Ankylosing spondylitis; Biologic therapy; Cost per responder; Indirect comparison; Network meta-analysis

\section{INTRODUCTION}

Ankylosing spondylitis (AS), a type of spondyloarthritis, is a chronic systemic rheumatic inflammatory disease of the axial skeleton, large peripheral joints, and entheses [1]. The principal feature of AS is inflammation of the sacroiliac joint at the base of the spine followed by rising inflammation along the spine, resulting in back pain and stiffness [2]. The standard of care for AS includes drugs such as non-steroidal anti-inflammatory drugs (NSAIDs), disease-modifying anti-rheumatic drugs (DMARDs), and non-drug interventions such as physical therapy. Although these drugs may offer palliation of symptoms, including spinal pain, peripheral joint pain, and physical function [1,3], none has been shown to alter the progression of AS.

AS is associated with significant direct medical costs in terms of medication, outpatient visits, hospitalizations, and alternative treatments [4]. In addition, given the progressive nature of AS and the related loss of functional ability, it leads to an increase in work disability and loss of productivity, particularly for individuals who undertake manual work [5]. Hence, AS is associated with a significant economic burden on both patients and society $[3,6]$. Effective treatment interventions can reduce the severity of the disease and increase patients' physical function and overall quality of life, while also improving work capacity and productivity [7].

Targeted biologic therapies have revolutionized the clinical management of AS. Currently, five different tumor necrosis factor
(TNF)- $\alpha$ inhibitors including adalimumab, certolizumab pegol, etanercept, golimumab, and infliximab are approved for the treatment of active AS (an infliximab biosimilar has also been approved, but is not currently marketed in the US). Secukinumab, an interleukin-17 inhibitor, was recently approved by the Food and Drug Administration (FDA) for the treatment of active AS [8]. Clinical trials have shown that these agents produce clinically important benefits to patients by improving physical functioning and reducing disease activity [9-13]. A previous meta-analysis synthesized data of different agents and concluded that TNF- $\alpha$ blockers improve disease activity and functional capacity for AS [14]. However, few head-to-head studies have directly compared the efficacy of these agents, and the comparative effectiveness among different biologic agents for AS treatment, especially for newer agents such as certolizumab pegol and secukinumab, is not well understood. Reliable evidence about the comparative effectiveness of these therapies is important to inform clinical and economic decisions regarding their use.

To fill these gaps, indirect comparisons of treatment outcomes across separate randomized trials can be used to provide valuable comparative evidence. Network meta-analysis is an approach that synthesizes information from several randomized comparisons to deliver internally consistent estimates of the treatment effects among competing interventions, while maintaining the randomization within each trial $[15,16]$. Detailed methodological reviews and implementation guidelines for network meta-analyses have been published $[15,17-19]$, and network meta-analyses have become a preferred source of comparative evidence for researchers, health-care decision 
makers, and health technology assessment agencies [15, 20, 21].

The objective of this study was to determine the relative efficacy of the six approved biologic agents for active AS using a network meta-analysis, and to evaluate the incremental cost per responder for these agents over a 12-week treatment period.

\section{METHODS}

\section{Trial Identification}

Phase III randomized clinical trials of TNF- $\alpha$ inhibitors (i.e., adalimumab, certolizumab pegol, etanercept, golimumab, and infliximab) and interleukin-17 inhibitors (i.e., secukinumab) for active AS were identified from a targeted literature review (January 1, 2000 to July 20, 2015). Trials were required to have been conducted among adult patients with active AS (defined as fulfilling the modified New York criteria for AS) [22]. Patients with non-radiographic axial spondylitis were excluded from this study. In addition, trials were required to be either placebo-controlled or a head-to-head comparison of two of the approved biologic agents. Trials were also required to have reported assessments in ankylosing spondylitis 20\% response (ASAS20) and/or 40\% response (ASAS40) at Week 12-16. Trial arms were required to use dose(s) approved by the FDA (e.g., adalimumab $40 \mathrm{mg}$ every other week, golimumab $50 \mathrm{mg}$ every month, and infliximab $5 \mathrm{mg} / \mathrm{kg}$ at 0,2 and 6 weeks, then every 6 weeks). For certolizumab pegol and etanercept, which have two approved dosing schedules (certolizumab pegol $400 \mathrm{mg}$ at week 0,2 , and 4 followed by either $200 \mathrm{mg}$ every other week or $400 \mathrm{mg}$ every 4 weeks, and etanercept $25 \mathrm{mg}$ twice weekly or etanercept
$50 \mathrm{mg}$ once weekly, respectively), these dosing schedules were assumed to be equivalent therapeutic doses and analyzed jointly in the analysis. For secukinumab, two approved dosing schedules were included in this studyone with a loading dosage (150 $\mathrm{mg}$ at Weeks 0 , $1,2,3,4$, and every 4 weeks thereafter) and one without a loading dosage (150 mg every 4 weeks). Secukinumab efficacy was evaluated collectively using the schedule with the loading dosage (the schedule with the loading dosage was examined during the double-blind placebo-controlled period in clinical trials, while the schedule without a loading dosage was evaluated among cross-over placebo patients), and costs were evaluated separately for the two secukinumab dosing schedules.

The study selection process was performed by two independent researchers with disagreements resolved by a third researcher. Data abstraction was performed by two independent researchers using a standardized data abstraction form.

\section{Efficacy Measures}

The ASAS criteria, the primary outcome in most AS trials, was used to define response [23]. ASAS20 is defined as an improvement of $20 \%$ (and absolute improvement of 10 units) in three of the four domains (patient global assessment, pain, function, and inflammation), and absence of deterioration in the potential remaining domain. ASAS40 is defined similarly with a required improvement of $40 \%$. The Committee for Medicinal Products for Human use (CHMP) has noted that the higher improvement of ASAS40 may be a more appropriate endpoint to evaluate biologic therapies [24], and ASAS40 may be associated with clinical meaningful improvements in health-related quality of life [25]. For the purpose of analysis, outcomes were 
evaluated at week 12 (when week 12 outcomes were not available, outcomes reported at week 14 or week 16 were substituted for the week 12 outcomes).

\section{Costs}

This study was conducted from a US payer perspective, and only biologic drug acquisition costs and associated administration costs were considered in the analysis. Unit drug costs as of July 20, 2015 were based on the US wholesale acquisition cost (WAC) obtained from ReadyPrice $^{\circledR}$ [26]. Based on the dosing schedules, unit costs, and administration costs, 12-week costs for each agent were calculated. The drug cost of infliximab was based on an 80-kg adult. Administration cost (intravenous infusion) for infliximab in the US as of July 20, 2015 was obtained from US Department of Health and Human Services (CPT code 96,413 for the initial hour and 96,415 for subsequent hours [27]). Infusion of infliximab was assumed to take $4 \mathrm{~h}[27,28]$.

\section{Statistical Methods}

A network meta-analysis was conducted to assess the comparative efficacy of the six approved biologic agents for the treatment of active AS. The network meta-analysis was conducted within a Bayesian approach, as this approach can deliver both statistical estimations and a framework for probabilistic decision-making under uncertainty [16]. Using a random effects model, the number of people achieving an ASAS20 (or ASAS40) response at Week 12-16 was assumed to follow a binomial likelihood, with the corresponding probabilities being related to the treatment effects via a logit link function. Assessment of the goodness-of-fit and model diagnostics was based on the residual deviance and the deviance information criterion.
Non-informative priors were applied to ensure that treatment comparisons were driven by the observed data. Estimated comparative effects were summarized using posterior medians and 95\% credible intervals (CrI). Numbers needed to treat (NNT) for each additional ASAS20 or ASAS40 responder were calculated as the reciprocal of the response rate difference between the agent and placebo. The incremental cost per responder for each treatment was calculated as the product of the 12-week costs and the NNT. Given that the efficacy measures from the clinical trials are based on intent-to-treat (ITT) analysis, the incremental costs per responder calculated in this study are also based on the ITT population. All analyses were conducted using Bayesian Markov chain Monte Carlo (MCMC) with OpenBUGS 3.2.3 [16].

\section{Compliance with Ethics Guidelines}

This article is based on previously conducted studies, and does not involve any new studies of human or animal subjects performed by any of the authors.

\section{RESULTS}

The targeted literature review identified 15 trials that met the inclusion criteria and reported ASAS20 and/or ASAS40 response rates from Week 12 to Week 16 after initiation of treatment (Table 1). Fourteen trials were placebo-controlled and one trial directly compared etanercept and infliximab [29]. Among the 14 placebo-controlled trials, adalimumab was investigated in 3 trials [9, 30, 31], certolizumab pegol in 1 trial [10], etanercept in 4 trials [11, 32-34], golimumab in 2 trials [12, 35], infliximab in 2 trials [13, 36], and secukinumab in 2 trials [37]. Figure 1 shows the evidence network of this study. All trials included were considered high quality, in terms 
Table 1 Summary of results from trials included in the network meta-analysis

\begin{tabular}{|c|c|c|c|c|c|c|}
\hline \multirow[t]{2}{*}{ Trial name } & \multirow[t]{2}{*}{ Treatment } & \multirow[t]{2}{*}{$N$} & \multicolumn{2}{|c|}{ ASAS20 at Week 12} & \multicolumn{2}{|c|}{ ASAS40 at Week 12} \\
\hline & & & $\bar{N}$ & $\%$ & $\bar{N}$ & $\%$ \\
\hline \multirow[t]{2}{*}{ ATLAS [9] } & Placebo & 107 & 22 & 20.6 & 14 & 13.1 \\
\hline & Adalimumab $40 \mathrm{mg}$ & 208 & 121 & 58.2 & 83 & 39.9 \\
\hline \multirow[t]{2}{*}{ M03-606 [30] } & Placebo & 44 & 12 & 27.3 & 4 & 9.1 \\
\hline & Adalimumab $40 \mathrm{mg}$ & 38 & 18 & 47.4 & 17 & 44.7 \\
\hline \multirow[t]{2}{*}{ Huang [31] } & Placebo & 115 & 35 & 30.4 & 11 & 9.6 \\
\hline & Adalimumab $40 \mathrm{mg}$ & 229 & 154 & 67.2 & 102 & 44.5 \\
\hline \multirow[t]{3}{*}{ RAPID-axSpA [10] } & Placebo & 57 & 21 & 36.8 & 11 & 19.3 \\
\hline & Certolizumab $200 \mathrm{mg}$ & 65 & 37 & 56.9 & 26 & 40.0 \\
\hline & Certolizumab $400 \mathrm{mg}$ & 56 & 36 & 64.3 & 28 & 50.0 \\
\hline \multirow[t]{2}{*}{ Calin [32] } & Placebo & 39 & 9 & 23.1 & - & - \\
\hline & Etanercept $25 \mathrm{mg}$ & 45 & 27 & 60.0 & - & - \\
\hline \multirow[t]{2}{*}{ Gorman $[33]^{a}$} & Placebo & 20 & 7 & 35.0 & - & - \\
\hline & Etanercept $25 \mathrm{mg}$ & 20 & 15 & 75.0 & - & - \\
\hline \multirow[t]{2}{*}{ Enbrel AS Study [11] } & Placebo & 139 & 39 & 28.1 & - & - \\
\hline & Etanercept $25 \mathrm{mg}$ & 138 & 82 & 59.4 & - & - \\
\hline \multirow[t]{3}{*}{ Etanercept Study 314 [34] } & Placebo & 51 & 19 & 37.3 & 11 & 21.6 \\
\hline & Etanercept $25 \mathrm{mg}$ & 150 & 107 & 71.3 & 80 & 53.3 \\
\hline & Etanercept $50 \mathrm{mg}$ & 155 & 115 & 74.2 & 90 & 58.1 \\
\hline \multirow[t]{2}{*}{ Giardina [29] } & Etanercept $50 \mathrm{mg}$ & 25 & 15 & 60.0 & 11 & 43.0 \\
\hline & Infliximab $5 \mathrm{mg} / \mathrm{kg}$ & 25 & 19 & 75.0 & 14 & 55.0 \\
\hline \multirow[t]{2}{*}{$\mathrm{Bao}[12]^{\mathrm{b}}$} & Placebo & 105 & 26 & 24.8 & 10 & 9.6 \\
\hline & Golimumab $50 \mathrm{mg}$ & 108 & 53 & 49.1 & 29 & 26.9 \\
\hline \multirow[t]{2}{*}{ GO-RAISE $[35]^{\mathrm{c}}$} & Placebo & 78 & 17 & 21.8 & 12 & 15.5 \\
\hline & Golimumab $50 \mathrm{mg}$ & 138 & 82 & 59.4 & 62 & 44.9 \\
\hline \multirow[t]{2}{*}{ ASSERT [13] } & Placebo & 78 & 16 & 20.5 & 10 & 12.8 \\
\hline & Infliximab $5 \mathrm{mg} / \mathrm{kg}$ & 201 & 124 & 61.9 & 99 & 49.3 \\
\hline \multirow[t]{2}{*}{ Braun [36] } & Placebo & 35 & 10 & 27.2 & - & - \\
\hline & Infliximab $5 \mathrm{mg} / \mathrm{kg}$ & 35 & 24 & 68.8 & - & - \\
\hline \multirow[t]{3}{*}{ MEASURE $1[37]^{\mathrm{d}}$} & Placebo & 122 & 35 & 28.7 & 16 & 13.1 \\
\hline & Secukinumab $75 \mathrm{mg}$ & 124 & 74 & 59.7 & 41 & 33.1 \\
\hline & Secukinumab $150 \mathrm{mg}$ & 125 & 76 & 60.8 & 52 & 41.6 \\
\hline
\end{tabular}


Table 1 continued

\begin{tabular}{|c|c|c|c|c|c|c|}
\hline \multirow[t]{2}{*}{ Trial name } & \multirow[t]{2}{*}{ Treatment } & \multirow[t]{2}{*}{$N$} & \multicolumn{2}{|c|}{ ASAS20 at Week 12} & \multicolumn{2}{|c|}{ ASAS40 at Week 12} \\
\hline & & & $N$ & $\%$ & $N$ & $\%$ \\
\hline \multirow[t]{3}{*}{ MEASURE $2[37]^{\mathrm{d}}$} & Placebo & 74 & 21 & 28.4 & 8 & 10.8 \\
\hline & Secukinumab $75 \mathrm{mg}$ & 73 & 30 & 41.1 & 19 & 26.0 \\
\hline & Secukinumab $150 \mathrm{mg}$ & 72 & 44 & 61.1 & 26 & 36.1 \\
\hline
\end{tabular}

${ }^{a}$ In this study, ASAS20 response was defined as $20 \%$ or greater improvement in at least three of five outcome measures (duration of morning stiffness, degree of nocturnal spinal pain, the Bath Ankylosing Spondylitis Functional Index, the patient's global assessment of disease activity, and the score for joint swelling)

b ASAS20 responses were assessed at week 14

c Efficacy outcomes were assessed at week 14

d Efficacy outcomes were assessed at week 16

of randomization, blinding, sample size, appropriate analysis, and data presentation, with the exception of the one open-label trial with a small sample size [29]. The majority of trials reported ASAS20 and/or ASAS40 at Week 12 , with the exception of the golimumab trial which reported ASAS20 and ASAS40 at Week 14, and the secukinumab trials which reported ASAS20 and ASAS40 at Week 16. The majority of trials were multi-center with the exception of two studies in China [12, 31], one study in Italy [30], one study in Canada [30], and one study in California, US [33]. In addition to fulfilling the modified New York criteria, the majority of trials required patients to have a Bath Ankylosing Spondylitis Disease Activity Index (BASDAI) greater than or equal to 4 , a spinal pain assessment score or a back pain score greater than or equal to 4 (on a 10-point visual analog scale or a 10-point numerical rating scale), and inadequate response to one or more NSAIDs. The certolizumab pegol and secukinumab trials enrolled patients with prior anti-TNF agent exposure $(20 \%$ in the RAPID-axSpA trial [10], 27\% in the MEASURE 1 trial [37], and 39\% in the MEASURE 2 trial [37]; ClinicalTrials.gov identifiers: NCT01087762, NCT01358175, and

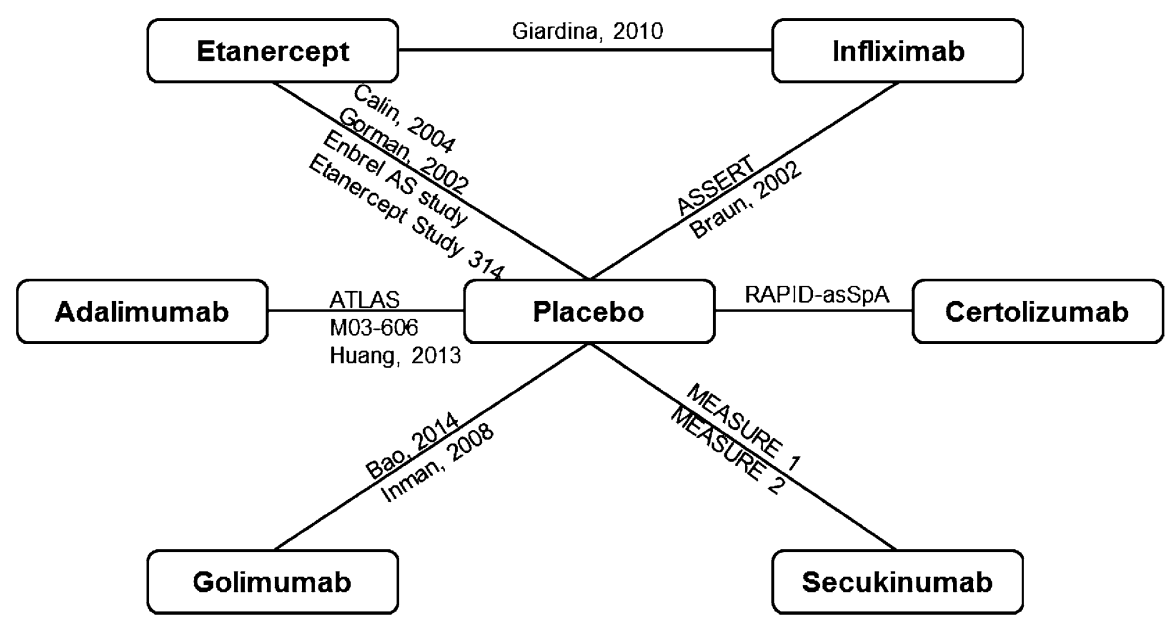

Fig. 1 Evidence network of biologic agents for treatment of active AS. A total of 15 phase III trials for active AS were identified through a targeted literature review and were included in the network. $A S$ ankylosing spondylitis 
NCT01649375, respectively), whereas all other agents were assessed in TNF-naïve populations.

\section{Network Meta-Analysis: ASAS20}

Patients with AS treated with infliximab had the highest probability of achieving ASAS20 (71.7\%; 95\% CrI 59.5-82.0\%) and the lowest NNT of 2.3 (95\% CrI 1.9-3.1), followed by those treated with adalimumab (ASAS20, 63.6\%; NNT, 2.8), etanercept (ASAS20, 62.0\%; NNT, 2.9), secukinumab (ASAS20, 60.3\%; NNT, 4.0), golimumab (ASAS20, 60.2\%; NNT, 3.1), and certolizumab pegol (ASAS20, 50.5\%; NNT, 4.4). Infliximab had a probability of $76 \%$ of having the highest ASAS20 response among all comparators, followed by adalimumab with a 9\% probability, and golimumab with a 5\% probability (Fig. 2a). Incorporating the cost component, adalimumab had the lowest 12-week cost per additional ASAS20 responder at \$26,888 (95\% CrI $\$ 21,720-\$ 37,320)$, followed by infliximab at $\$ 28,175 \quad(\$ 22,903-\$ 38,694)$, etanercept at $\$ 28,199 \quad(\$ 22,483-\$ 38,633)$, golimumab at $\$ 30,417 \quad(\$ 22,550-\$ 49,510)$, secukinumab without a loading dosage at $\$ 33,847$ $(\$ 25,149-\$ 53,293)$, certolizumab pegol at $\$ 60,326$ (\$33,593-\$232,542), and secukinumab with a loading dosage at $\$ 67,694$ $(\$ 50,299-\$ 106,586)$. Adalimumab had a probability of $38 \%$ of having the lowest cost per ASAS20 responder among all comparators, followed by etanercept with a $22 \%$ probability, infliximab with a $21 \%$ probability, and golimumab with a $14 \%$ probability (Fig. 2 b). Detailed results of the network meta-analysis of ASAS20 for all agents are shown in Table 2.

\section{Network Meta-Analysis: ASAS40}

Patients with AS treated with infliximab had the highest probability of achieving ASAS40 (51.5\%;
95\% CrI 33.4-70.0\%) and the lowest NNT of 2.6 (95\% CrI 1.8-4.9), followed by adalimumab (ASAS40, 49.2\%; NNT, 2.8), secukinumab (ASAS40, 42.4\%; NNT, 3.5), etanercept (ASAS40, 41.4\%; NNT, 3.6), golimumab (ASAS40, 38.6\%; NNT, 4.0), and certolizumab pegol (ASAS40, 34.8\%; NNT, 4.7). Infliximab had a probability of $48 \%$ of having the highest ASAS40 response among all comparators, followed by adalimumab with a probability of $29 \%$, secukinumab with a $9 \%$ probability, and etanercept with a $6 \%$ probability. Incorporating the cost component, adalimumab had the lowest 12-week cost per additional ASAS40 responder at $\$ 26,898 \quad(95 \% \quad \mathrm{CrI}$ $\$ 19,483-\$ 41,699)$, followed by infliximab at $\$ 32,508 \quad(\$ 21,954-\$ 60,308)$, etanercept at $\$ 34,406 \quad(\$ 20,866-\$ 76,436)$, secukinumab without a loading dosage at $\$ 37,850$ $(\$ 24,274-\$ 72,096)$, golimumab at $\$ 39,030$ $(\$ 23,760-\$ 83,570)$, certolizumab pegol at $\$ 64,051$ (\$31,815-\$227,020), and secukinumab with a loading dosage at $\$ 75,701$ $(\$ 48,547-\$ 144,191)$. Adalimumab had a probability of $56 \%$ of having the lowest cost per ASAS40 responder among all comparators, followed by infliximab with a $17 \%$ probability, etanercept with a $14 \%$ probability, secukinumab without a loading dosage with a $7 \%$ probability, and golimumab with a $6 \%$ probability. Detailed results of the network meta-analysis of ASAS40 for all agents are shown in Table 3.

\section{DISCUSSION}

The primary goal of AS treatment is to relieve symptoms, maintain physical function, and prevent complications [1]. The assessment in ankylosing spondylitis (ASAS) group recommended that physical function, spinal pain, patient global assessment, and 


\section{a ASAS20 response}

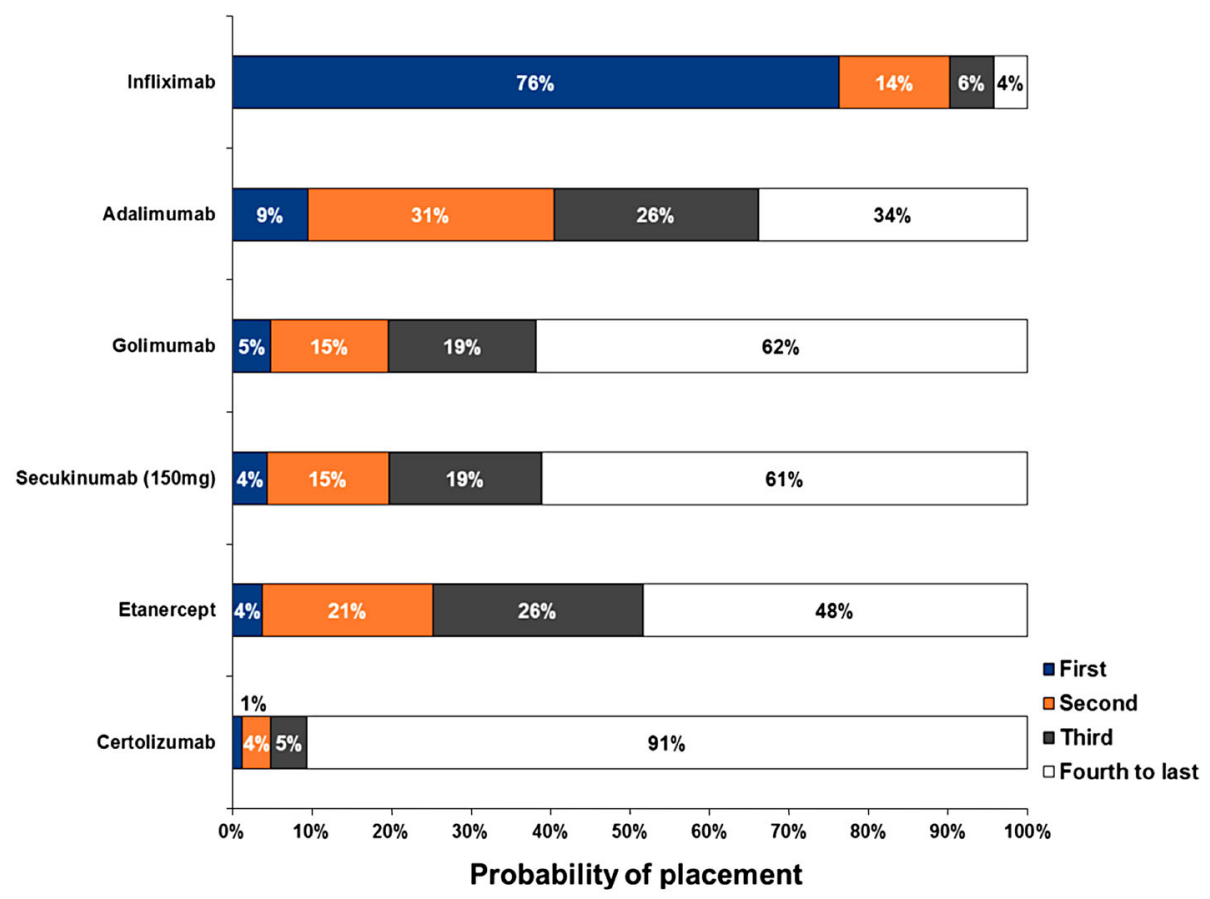

\section{b Cost per ASAS20 responder}

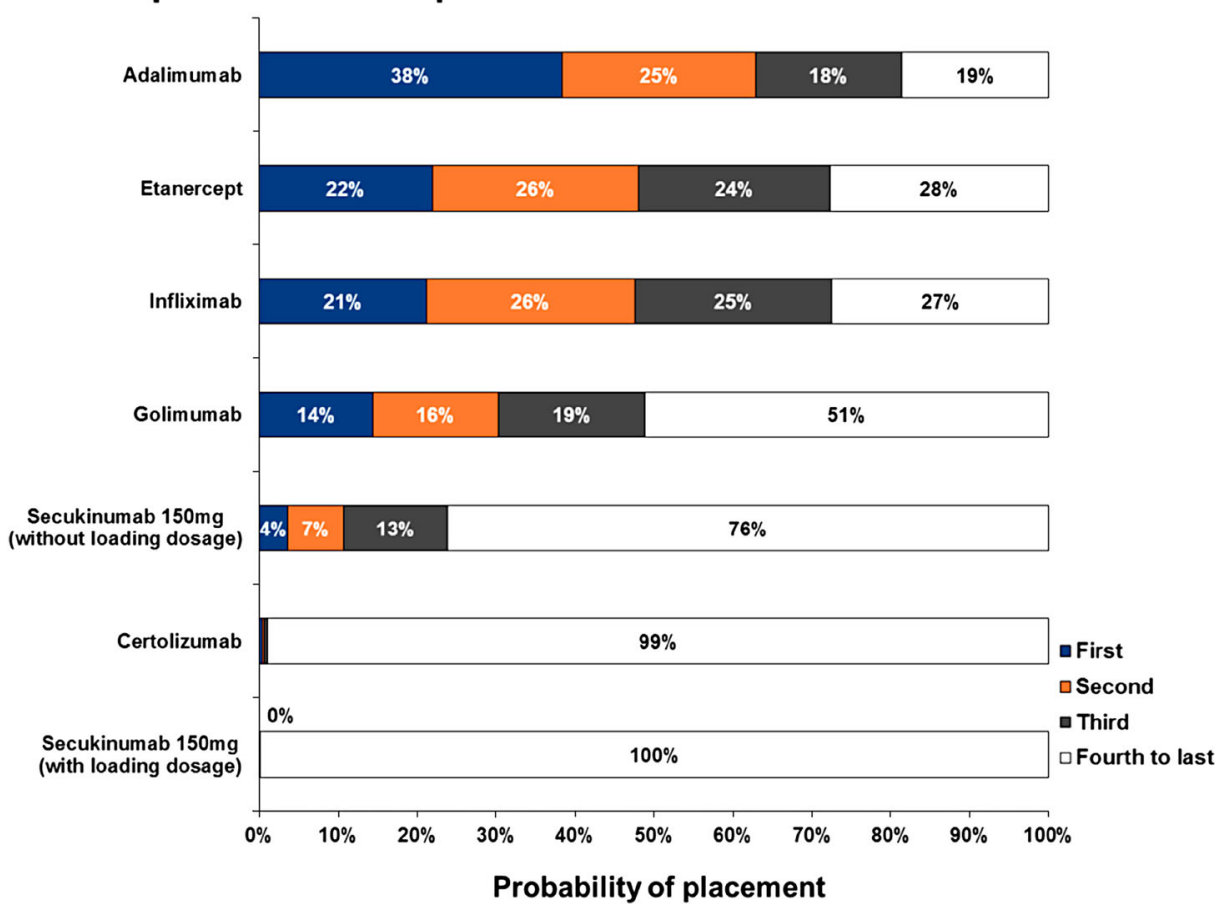

Fig. 2 Ranking probabilities of biologic agents for treatment of active ankylosing spondylitis. a Ranking probabilities in ASAS20 response. b Ranking probabilities in cost per ASAS20 responder 
inflammation to be the core set of criteria to evaluate AS treatment response, and used them to construct composite criteria for use in AS trials [38]. ASAS20 and ASAS40 are among these composite criteria, which have been validated in previous studies of TNF blockers and are widely used in AS clinical trials [39]. In the current network meta-analysis of biologic treatments for active AS, infliximab had the lowest NNT to achieve an additional ASAS20/40 response, and adalimumab had the lowest 12-week cost per ASAS20/40 responder.

Previous research has assessed the efficacy of different biologic agents in the treatment of AS using conventional pairwise meta-analyses. One study compared adalimumab, etanercept, and infliximab with placebo, and found that these TNF inhibitors had significantly better efficacy than placebo, in terms of pain, physical function, patient's global assessment, and acute phase reactants [40]. Other more recent studies assessed the efficacy of TNF blockers as a class by pooling studies of different agents together (adalimumab, certolizumab pegol, etanercept, golimumab, and infliximab) $[3,14,41]$. In those studies, TNF inhibitors showed better efficacy than placebo for BASDAI, Bath Ankylosing Spondylitis Functional Index (BASFI), Bath Ankylosing Spondylitis Metrology Index (BASMI), ASAS20, ASAS40, ASAS50, and ASAS70 response among patients with AS. One previous indirect comparison study assessed the relative efficacies among adalimumab, etanercept, golimumab, and infliximab [42]. However, that study only evaluated ASAS20 and did not include the newer biologic agents (certolizumab pegol and secukinumab); moreover, it did not take drug cost into consideration in the comparisons. A recent report by the National Institute for Health and

Table 2 Number needed to treat and cost per ASAS20 responder

\begin{tabular}{|c|c|c|c|c|}
\hline Treatment & Response (95\% CrI) & $\begin{array}{l}\text { OR } \\
(95 \% \mathrm{CrI})\end{array}$ & $\begin{array}{l}\text { NNT } \\
(95 \% \text { CrI })\end{array}$ & $\begin{array}{l}\text { Cost per responder } \\
(95 \% \mathrm{CrI})\end{array}$ \\
\hline Placebo & $27.9 \%(25.3 \%, 30.6 \%)$ & - & - & - \\
\hline Adalimumab & $63.6 \%(53.2 \%, 72.5 \%)$ & $4.5(3.0,6.7)$ & $2.8(2.3,3.9)$ & $\$ 26,888(\$ 21,720, \$ 37,320)$ \\
\hline Certolizumab pegol $^{\mathrm{a}}$ & $50.5 \%(32.9 \%, 68.4 \%)$ & $2.6(1.3,5.5)$ & $4.4(2.5,17.0)$ & $\$ 60,326(\$ 33,593, \$ 232,542)$ \\
\hline Etanercept ${ }^{b}$ & $62.0 \%(52.3 \%, 71.1 \%)$ & $4.2(2.9,6.2)$ & $2.9(2.3,4.0)$ & $\$ 28,199(\$ 22,483, \$ 38,633)$ \\
\hline Golimumab & $60.2 \%(47.4 \%, 71.8 \%)$ & $3.9(2.4,6.5)$ & $3.1(2.3,5.0)$ & $\$ 30,417(\$ 22,550, \$ 49,510)$ \\
\hline Infliximab $^{c}$ & $71.7 \%(59.5 \%, 82.0 \%)$ & $6.6(3.9,11.6)$ & $2.3(1.9,3.1)$ & $\$ 28,175(\$ 22,903, \$ 38,694)$ \\
\hline $\begin{array}{l}\text { Secukinumab } \\
\text { (without loading) }^{\mathrm{d}}\end{array}$ & $60.3 \%(48.1 \%, 71.8 \%)$ & $4.0(2.3,6.6)$ & $3.1(2.3,5.1)$ & $\$ 33,847(\$ 25,149, \$ 53,293)$ \\
\hline Secukinumab (with loading) ${ }^{\mathrm{d}}$ & $60.3 \%(48.1 \%, 71.8 \%)$ & $4.0(2.3,6.6)$ & $3.1(2.3,5.1)$ & $\$ 67,694(\$ 50,299, \$ 106,586)$ \\
\hline \multicolumn{5}{|c|}{$\begin{array}{l}\text { ASAS20 assessment in ankylosing spondylitis } 20 \% \text { response, } C r I \text { credible interval, } N N T \text { number needed to treat, } O R \text { odds } \\
\text { ratio } \\
\text { Efficacies were estimated based on a random effects network meta-analysis using a binomial model } \\
\text { a Certolizumab pegol } 200 \mathrm{mg} \text { every } 2 \text { weeks and } 400 \mathrm{mg} \text { every } 4 \text { weeks were treated as equivalent therapeutic doses } \\
\text { b Etanercept } 25 \mathrm{mg} \text { twice a week and } 50 \mathrm{mg} \text { every week were treated as equivalent therapeutic doses } \\
\text { c Drug cost of infliximab was based on an } 80 \mathrm{~kg} \text { adult } \\
\text { d Assumes that the efficacy of secukinumab } 150 \mathrm{mg} \text { was equivalent with and without a loading dose }\end{array}$} \\
\hline
\end{tabular}


Table 3 Number needed to treat and cost per ASAS40 responder

\begin{tabular}{|c|c|c|c|c|}
\hline Treatment & Response (95\% CrI) & $\begin{array}{l}\text { OR }(95 \% \\
\text { CrI })\end{array}$ & $\begin{array}{l}\text { NNT }(95 \% \\
\text { CrI })\end{array}$ & $\begin{array}{l}\text { Cost per responder }(95 \% \\
\text { CrI })\end{array}$ \\
\hline Placebo & $13.5 \%(11.4 \%, 15.9 \%)$ & - & - & - \\
\hline Adalimumab & $49.2 \%(36.0 \%, 63.4 \%)$ & $6.2(3.8,10.8)$ & $2.8(2.0,4.3)$ & $\$ 26,898(\$ 19,483, \$ 41,699)$ \\
\hline Certolizumab pegol $^{a}$ & $34.8 \%(18.8 \%, 56.2 \%)$ & $3.4(1.5,8.1)$ & $4.7(2.3,16.6)$ & $\$ 64,051(\$ 31,815, \$ 227,020)$ \\
\hline Etanercept ${ }^{\mathrm{b}}$ & $41.4 \%(25.6 \%, 60.1 \%)$ & $4.6(2.3,9.3)$ & $3.6(2.2,8.0)$ & $\$ 34,406(\$ 20,866, \$ 76,436)$ \\
\hline Golimumab & $38.6 \%(24.5 \%, 55.5 \%)$ & $4.0(2.2,7.8)$ & $4.0(2.4,8.5)$ & $\$ 39,030(\$ 23,760, \$ 83,570)$ \\
\hline Infliximab $^{c}$ & $51.5 \%(33.4 \%, 70.0 \%)$ & $6.8(3.3,14.8)$ & $2.6(1.8,4.9)$ & $\$ 32,508(\$ 21,954, \$ 60,308)$ \\
\hline $\begin{array}{l}\text { Secukinumab (without } \\
\text { loading) }\end{array}$ & $42.4 \%(28.1 \%, 59.2 \%)$ & $4.7(2.6,9.1)$ & $3.5(2.2,6.6)$ & $\$ 37,850(\$ 24,274, \$ 72,096)$ \\
\hline Secukinumab (with loading) ${ }^{\mathrm{d}}$ & $42.4 \%(28.1 \%, 59.2 \%)$ & $4.7(2.6,9.1)$ & $3.5(2.2,6.6)$ & $\$ 75,701(\$ 48,547, \$ 144,191)$ \\
\hline \multicolumn{5}{|c|}{$\begin{array}{l}\text { ASAS40 assessment in ankylosing spondylitis } 40 \% \text { response, } C r I \text { credible interval, NNT number needed to treat, OR } \\
\text { ratio } \\
\text { Efficacies were estimated based on a random effects network meta-analysis using a binomial model } \\
\text { a Certolizumab pegol } 200 \mathrm{mg} \text { every } 2 \text { weeks and } 400 \mathrm{mg} \text { every } 4 \text { weeks were treated as equivalent therapeutic doses } \\
\text { b Etanercept } 25 \mathrm{mg} \text { twice a week and } 50 \mathrm{mg} \text { every week were treated as equivalent therapeutic doses } \\
\text { c Drug cost of infliximab was based on an } 80 \mathrm{~kg} \text { adult } \\
\text { d Assumes that the efficacy of secukinumab } 150 \mathrm{mg} \text { was equivalent with and without a loading dose }\end{array}$} \\
\hline
\end{tabular}

Care Excellence (NICE) assessed data from sixteen randomized clinical trials via a network meta-analysis and compared the efficacy of adalimumab, certolizumab pegol, etanercept, golimumab, and infliximab in the treatment of AS [43]. The results in the NICE report are in line with the ones presented in this study, in terms of both ASAS20 and ASAS40 (that report did not include data regarding the newer agent secukinumab). The current analyses are the first to compare the efficacy and cost-effectiveness among a comprehensive list of novel biologic agents for active AS treatment. This study indicated that adalimumab had the lowest overall cost per responder in the treatment of active AS (when considering both ASAS20 and ASAS40 response), which is consistent with previous studies regarding the cost per responder associated with biologic therapies for Crohn's disease, psoriasis, and rheumatoid arthritis $[44,45]$.

The recently published 2015 American College of Rheumatology (ACR)/Spondylitis Association of America (SAA)/Spondyloarthritis Research and Treatment Network (SPARTAN) guidelines for the treatment of AS recommend TNF inhibitors in adults with AS when activity persists despite treatment with NSAIDs [46]. The guidelines do not recommend a particular TNF inhibitor, except in patients with AS and inflammatory bowel disease where treatment with TNF inhibitory monoclonal antibodies (such as adalimumab or infliximab) is preferred over etanercept. While the guidelines do not include secukinumab, the FDA suggested cautious use of secukinumab in patients with inflammatory bowel disease due to exacerbations observed during the clinical trials [8]. 
As in other indirect comparison studies, this network meta-analysis also has some limitations. Given the small numbers of eligible trials for each pairwise comparison in the network, appropriate adjustment of baseline risks for each trial was rendered impossible. In addition, although the network meta-analysis synthesizes results from randomized clinical trials, the comparative efficacy was mostly based on indirect evidence, and may be influenced by potentially observed or unobserved differences across the trials. However, this network meta-analysis represents the best evidence available for the comparative efficacy of biologic treatment for active AS, and this information is crucial for health technology assessment and other decision-making in this field. In addition, this study included one open-label trial with limited sample size comparing etanercept with infliximab [29]. The responses reported in this trial, however, are similar to the results from the current network meta-analysis. Therefore, including this study will not significantly affect the estimates in this study and may in fact strengthen the analysis by directly linking two of the biologic agents.

Most of the AS clinical trials included in this analysis allowed concomitant use of DMARDs (e.g., sulfasalazine, methotrexate) and corticosteroids; however, the cost per responder analyses include only the biologic drug costs (and associated administration cost). This study did not consider direct medical costs associated with treatment, such as those associated with hospitalization and rheumatology visits. Moreover, this analysis did not compare safety and tolerability outcomes, and thus, did not include subsequent costs associated with potential adverse events. Nonetheless, most of the biologic agents did not show significantly different rates of serious adverse events compared with placebo (except for certolizumab pegol) in a Cochran meta-analysis of clinical trials data [47], and rates of concomitant use of DMARDs and corticosteroids were similar across trials so the inclusion of these outcomes and associated costs would be unlikely to alter the conclusions of this study. To be consistent with the primary endpoints of AS clinical trials, this study only considers 12 -week costs for all treatments and does not speculate on the cost-effectiveness over longer periods of treatment. Future economic modeling studies may be helpful in understanding the full picture of healthcare costs associated with biologic treatments of AS. Lastly, the lack of certolizumab pegol trial results stratified by previous TNF inhibitor exposure limited the ability to conduct the analysis in a pure TNF-naïve population. As the proportion of patients with prior TNF exposure is relatively small and the exposure would affect both the placebo and the active agent, the results are unlikely to be markedly affected by the inclusion of TNF-experienced patients for certolizumab pegol and secukinumab.

\section{CONCLUSIONS}

The current analyses are the first to compare the efficacy and cost-effectiveness among all available biologic agents for the treatment of active AS. In these analyses, adalimumab and infliximab demonstrated higher efficacy and lower cost per responder in terms of both ASAS20 and ASAS40. The study results indicate the potential for these agents to be used more cost-effectively in the treatment of active AS. 


\section{ACKNOWLEDGMENTS}

The design, study conduct, and financial support for the study were provided by AbbVie. AbbVie participated in the interpretation of data, review, and approval of the publication. All named authors meet the International Committee of Medical Journal Editors (ICMJE) criteria for authorship for this manuscript, take responsibility for the integrity of the work as a whole, and have given final approval to the version to be published.

Disclosures. Keith Betts, Yan Song, and Eric Wu have served as consultants to AbbVie. Jenny Griffith, Manish Mittal, Avani Joshi, and Arijit Ganguli are employees of AbbVie and may own company stock.

Compliance with Ethics Guidelines. This article is based on previously conducted studies, and does not involve any new studies of human or animal subjects performed by any of the authors.

Open Access. This article is distributed under the terms of the Creative Commons AttributionNonCommercial 4.0 International License (http://creativecommons.org/licenses/by-nc/4. $0 /$ ), which permits any noncommercial use, distribution, and reproduction in any medium, provided you give appropriate credit to the original author(s) and the source, provide a link to the Creative Commons license, and indicate if changes were made.

\section{REFERENCES}

1. McVeigh CM, Cairns AP. Diagnosis and management of ankylosing spondylitis. BMJ. 2006;333:581-5.
2. Dakwar E, Reddy J, Vale FL, Uribe JS. A review of the pathogenesis of ankylosing spondylitis. Neurosurg Focus. 2008;24:E2.

3. McLeod C, Bagust A, Boland A, et al. Adalimumab, etanercept and infliximab for the treatment of ankylosing spondylitis: a systematic review and economic evaluation. Health Technol Assess. 2007;11:1-158, iii-iv.

4. Greenberg JD, Palmer JB, Li Y, Herrera V, Tsang Y, Liao M. Healthcare resource use and direct costs in patients with ankylosing spondylitis and psoriatic arthritis in a large US cohort. J Rheumatol. 2016;43:88-96.

5. Martindale J, Shukla R, Goodacre J. The impact of ankylosing spondylitis/axial spondyloarthritis on work productivity. Best Pract Res Clin Rheumatol. 2015;29:512-23.

6. Reveille JD, Ximenes A, Ward MM. Economic considerations of the treatment of ankylosing spondylitis. Am J Med Sci. 2012;343:371-4.

7. Kobelt G, Andlin-Sobocki P, Brophy S, Jonsson L, Calin A, Braun J. The burden of ankylosing spondylitis and the cost-effectiveness of treatment with infliximab (Remicade). Rheumatology (Oxford). 2004;43:1158-66.

8. Cosentyx $(\mathrm{R}) \quad$ [package insert]. Novartis Pharmaceuticals, Inc., Basel, Switzerland; http:// www.pharma.us.novartis.com/product/pi/pdf/cose ntyx.pdf. Accessed Mar 14, 2016.

9. van der Heijde D, Kivitz A, Schiff MH, et al. Efficacy and safety of adalimumab in patients with ankylosing spondylitis: results of a multicenter, randomized, double-blind, placebo-controlled trial. Arthritis Rheum. 2006;54:2136-46.

10. Landewe R, Braun J, Deodhar A, et al. Efficacy of certolizumab pegol on signs and symptoms of axial spondyloarthritis including ankylosing spondylitis: 24-week results of a double-blind randomised placebo-controlled Phase 3 study. Ann Rheum Dis. 2014;73:39-47.

11. Davis JC Jr, Van Der Heijde D, Braun J, et al. Recombinant human tumor necrosis factor receptor (etanercept) for treating ankylosing spondylitis: a randomized, controlled trial. Arthritis Rheum. 2003;48:3230-6.

12. Bao C, Huang F, Khan MA, et al. Safety and efficacy of golimumab in Chinese patients with active ankylosing spondylitis: 1-year results of a multicentre, randomized, double-blind, placebo-controlled phase III trial. Rheumatology (Oxford). 2014;53:1654-63. 
13. van der Heijde D, Dijkmans B, Geusens P, et al. Efficacy and safety of infliximab in patients with ankylosing spondylitis: results of a randomized, placebo-controlled trial (ASSERT). Arthritis Rheum. 2005;52:582-91.

14. Callhoff J, Sieper J, Weiss A, Zink A, Listing J. Efficacy of TNFalpha blockers in patients with ankylosing spondylitis and non-radiographic axial spondyloarthritis: a meta-analysis. Ann Rheum Dis. 2015;74:1241-8.

15. Jansen JP, Fleurence R, Devine B, et al. Interpreting indirect treatment comparisons and network meta-analysis for health-care decision making: report of the ISPOR Task Force on Indirect Treatment Comparisons Good Research Practices: part 1. Value Health. 2011;14:417-28.

16. Dias S, Welton NJ, Sutton AJ, Ades A. NICE DSU Technical Support Document 2: a generalised linear modelling framework for pairwise and network meta-analysis of randomised controlled trials. London: National Institute for Health and Clinical Excellence; 2011.

17. Wells GA, Sultan SA, Chen L, Khan M, Coyle D. Indirect evidence: indirect treatment comparisons in meta-analysis. Ottawa: Canadian Agency for Drugs and Technologies in Health; 2009.

18. Dias S, Welton NJ, Sutton AJ, Ades AE. NICE DSU technical support document 1: introduction to evidence synthesis for decision making 2011 [cited 2015 Dec 29]. http://www.nicedsu.org.uk/ TSD1\%20Introduction.final.08.05.12.pdf.

19. Glenny AM, Altman DG, Song F, et al. Indirect comparisons of competing interventions. Health Technol Assess. 2005;9:1-134, iii-iv.

20. Sutton A, Ades A, Cooper N, Abrams K. Use of indirect and mixed treatment comparisons for technology assessment. Pharmacoeconomics. 2008;26:753-67.

21. Guide to the methods of technology appraisal 2013. https://www.nice.org.uk/article/pmg9/chapter/Fore word. Accessed 14 Mar 2016.

22. van der Linden S, Valkenburg HA, Cats A. Evaluation of diagnostic criteria for ankylosing spondylitis. A proposal for modification of the New York criteria. Arthritis Rheum. 1984;27:361-8.

23. Anderson JJ, Baron G, van der Heijde D, Felson DT, Dougados M. Ankylosing spondylitis assessment group preliminary definition of short-term improvement in ankylosing spondylitis. Arthritis Rheum. 2001;44:1876-86.
24. European Medicines Agency. Guideline on clinical investigation of medicinal products for the treatment of ankylosing spondylitis 2009 [cited 2015 Dec 29]. http://www.ema.europa.eu/docs/en GB/document_library/Scientific_guideline/2009/09/ WC500003424.pdf.

25. van der Heijde D, Joshi A, Pangan AL, et al. ASAS40 and ASDAS clinical responses in the ABILITY-1 clinical trial translate to meaningful improvements in physical function, health-related quality of life and work productivity in patients with non-radiographic axial spondyloarthritis. Rheumatology (Oxford). 2016;55:80-8.

26. Red Book Online ${ }^{\circledR} 2015$ [cited 2015 December 2]. http://www.redbook.com/redbook/.

27. Johnson \& Johnson Health Care Systems Inc. Reimbursement Resources (Remicade) 2015 [cited 2015 May 18]. https://www.janssenaccessone.com/ pages/remicade/guide/reimbursement/reimburse ment.jsp.

28. Feldman SR, Garton R, Averett W, Balkrishnan R, Vallee J. Strategy to manage the treatment of severe psoriasis: considerations of efficacy, safety and cost. Expert Opin Pharmacother. 2003;4:1525-33.

29. Giardina AR, Ferrante A, Ciccia F, et al. A 2-year comparative open label randomized study of efficacy and safety of etanercept and infliximab in patients with ankylosing spondylitis. Rheumatol Int. 2010;30:1437-40.

30. Lambert RG, Salonen D, Rahman $\mathrm{P}$, et al. Adalimumab significantly reduces both spinal and sacroiliac joint inflammation in patients with ankylosing spondylitis: a multicenter, randomized, double-blind, placebo-controlled study. Arthritis Rheum. 2007;56:4005-14.

31. Huang F, Gu J, Zhu P, et al. Efficacy and safety of adalimumab in Chinese adults with active ankylosing spondylitis: results of a randomised, controlled trial. Ann Rheum Dis. 2014;73:587-94.

32. Calin A, Dijkmans BA, Emery P, et al. Outcomes of a multicentre randomised clinical trial of etanercept to treat ankylosing spondylitis. Ann Rheum Dis. 2004;63:1594-600.

33. Gorman JD, Sack KE, Davis JC Jr. Treatment of ankylosing spondylitis by inhibition of tumor necrosis factor alpha. $\mathrm{N}$ Engl J Med. 2002;346:1349-56.

34. van der Heijde D, Da Silva JC, Dougados M, et al. Etanercept $50 \mathrm{mg}$ once weekly is as effective as $25 \mathrm{mg}$ twice weekly in patients with ankylosing spondylitis. Ann Rheum Dis. 2006;65:1572-7. 
35. Inman RD, Davis JC Jr, Heijde D, et al. Efficacy and safety of golimumab in patients with ankylosing spondylitis: results of a randomized, double-blind, placebo-controlled, phase III trial. Arthritis Rheum. 2008;58:3402-12.

36. Braun J, Brandt J, Listing J, et al. Treatment of active ankylosing spondylitis with infliximab: a randomised controlled multicentre trial. Lancet. 2002;359:1187-93.

37. Baeten D, Sieper J, Braun J, et al. Secukinumab, an Interleukin-17A Inhibitor, in Ankylosing Spondylitis. N Engl J Med. 2015;373:2534-48.

38. Zochling J, Braun J. Assessment of ankylosing spondylitis. Clin Exp Rheumatol. 2005;23:S133-41.

39. Stone MA, Inman RD, Wright JG, Maetzel A. Validation exercise of the ankylosing spondylitis assessment study (ASAS) group response criteria in ankylosing spondylitis patients treated with biologics. Arthritis Rheum. 2004;51:316-20.

40. Escalas C, Trijau S, Dougados M. Evaluation of the treatment effect of NSAIDs/TNF blockers according to different domains in ankylosing spondylitis: results of a meta-analysis. Rheumatology (Oxford). 2010;49:1317-25.

41. Machado MA, Barbosa MM, Almeida AM, et al. Treatment of ankylosing spondylitis with TNF blockers: a meta-analysis. Rheumatol Int. 2013;33: 2199-213.
42. Shu T, Chen GH, Rong L, et al. Indirect comparison of anti-TNF-alpha agents for active ankylosing spondylitis: mixed treatment comparison of randomized controlled trials. Clin Exp Rheumatol. 2013;31:717-22.

43. Corbett M, Soares M, Jhuti G, Rice S, Spackman E, Sideris E. tnf-alpha inhibitors for ankylosing spondylitis and axial spondyloarthritis without radiographic evidence of ankylosing spondylitis. Cochrane Assessment Report. 2014.

44. Liu Y, Wu EQ, Bensimon AG, et al. Cost per responder associated with biologic therapies for Crohn's disease, psoriasis, and rheumatoid arthritis. Adv Ther. 2012;29:620-34.

45. Cheng J, Feldman SR. The cost of biologics for psoriasis is increasing. Drugs Context. $2014 ; 3: 212266$.

46. Ward MM, Deodhar A, Akl EA, et al. American College of Rheumatology/Spondylitis Association of America/Spondyloarthritis Research and Treatment Network 2015 Recommendations for the treatment of ankylosing spondylitis and nonradiographic axial spondyloarthritis. Arthritis Rheumatol. 2015;68:282-98.

47. Singh JA, Wells GA, Christensen R, et al. Adverse effects of biologics: a network meta-analysis and Cochrane overview. Cochrane Database Syst Rev. 2011:CD008794. 